2018

\title{
Curbing Catastrophe: Communicating about Natural Hazards
}

Timothy H. Dixon

University of South Florida, thd@usf.edu

\section{Recommended Citation}

Dixon, Timothy H.. "Curbing Catastrophe: Communicating about Natural Hazards." Numeracy 11, Iss. 2 (2018): Article 8. DOI: https://doi.org/10.5038/1936-4660.11.2.8 


\title{
Curbing Catastrophe: Communicating about Natural Hazards
}

\author{
Abstract \\ Timothy H. Dixon. 2017. Curbing Catastrophe: Natural Hazards and Risk Reduction in the Modern World. \\ (New York, NY: Cambridge University Press) 300 pp. ISBN 978-1108113663.
}

Despite all we know scientifically about geologic and other natural hazards, why is it that they continue to wreak havoc on humankind? Spurred initially by Fukushima (Japan, 2011) and Katrina (New Orleans, 2005), I have concluded that three factors are key: the lack of communication between experts, public and policy makers, especially when to comes to scientific concepts; time lags; and the need to consider longterm economic consequences. Earth scientists often think in terms of decades, centuries and longer, but for most people, long time scales are pretty abstract. Thus my book underscores the perils of ignoring the need for critical infrastructure. The issue is particularly acute for disasters associated with the hazard of climate change - the subject of my excerpt from Chapter 8 , "What's All the Fuss about Climate Warming?"

\section{Keywords}

quantitative literacy - communication; natural disasters; geohazards; climate change; global warming; Fukushima; Hurricane Katrina

\section{Creative Commons License}

\section{(c) () 8}

This work is licensed under a Creative Commons Attribution-Noncommercial 4.0 License

\section{Cover Page Footnote}

Tim Dixon is a Professor of Geology and Geophysics in the School of Geosciences at the University of South Florida - Tampa. His research uses satellite geodesy and remote sensing data to study Earth surface and subsurface processes, including earthquakes and volcano deformation, mountain building, coastal subsidence, large-scale groundwater extraction, and glacier motion. Before joining USF in 2011, he was on the senior faculty at the Rosenstiel School of Marine and Atmospheric Sciences (University of Miami) for eight years, following 13 years in space geodesy and geodynamics at the Jet Propulsion Laboratory (Pasadena CA). A certified pilot and advanced SCUBA diver, Dixon is a Fellow of the Geologic Society of America (GSA), the American Geophysical Union (AGU), and the American Association for the Advancement of Science (AAS). As of this summer, nine PhD students have completed their research with Tim as advisor or co-advisor (RSMAS and USF), and more are on the way. 


\section{Overview}

When I was first asked to write a book about natural hazards, I declined - the topic seemed to be covered by dozens of existing, well-written books, carefully enumerating all the various ways that nature wreaks havoc on humankind and our infrastructure. On thinking about it some more, I realized there was one topic that was not well addressed why does nature continue to wreak havoc, despite all of our supposed knowledge (and all those books)? We've known about floods and volcanoes for hundreds of years Machiavelli weighed in on flood prevention in his famous book The Prince, published in 1532. We've had pretty good scientific understanding of these and other natural processes for at least four or five decades. We've even had some forecast capability for many hazards for a few decades. So what gives?

Japan's great Tohoku earthquake in 2011 and the resulting disaster at the Fukushima nuclear plant helped to clarify my thinking. Just because experts know that a disaster is virtually inevitable at a given location (there were lots of indications that this part of Japan's coast was tsunami-prone), they may have trouble communicating that knowledge to key people. They may also know the "where" but not the "when"; the lack of immediacy makes preventive action seem less important to the higher-ups (management and politicians) especially if it's going to cost money. The same problems contributed to flooding of New Orleans during Hurricane Katrina six years before Fukushima. Although the geology was different, the hubris and mismanagement were the same. Fukushima was Japan's costliest disaster, Katrina was America's. Both were largely avoidable. Experts knew that the levees surrounding New Orleans were too low, but no one wanted to spend the money to fix them. New Orleans and Fukushima have another sad fact in common - key pumping stations or their electrical control systems that were supposed to keep critical infrastructure safe from flooding were located at elevations too low to withstand flood water - a fatal (and let's be blunt, really dumb) mistake. So what's going on? Why do we keep making the same mistakes when it comes to dealing with Mother Nature?

In addition to Fukushima and New Orleans, other examples in the book tend to bring out the same reaction in readers - looking back, we tend to ask "How could they be so short-sighted?" where "they" means managers and politicians. Part of the answer is that disasters always look preventable in hindsight. We need to ask ourselves what new disasters might be coming our way that could be avoided or minimized if we take the right action. To help answer that question, I went back and looked at some common factors contributing to past mishaps. Three stood out:

1. communication (or more specifically its lack) between experts, the public, and policy makers, especially when to comes to scientific concepts;

2. the importance of time lag;

3. the importance of considering long-term economic consequences. Earth scientists often think in terms of decades, centuries and longer, but for most people, such long time scales are pretty abstract.

The three factors are not independent. I illustrate this in Chapter 8, the one that deals with climate change. This topic is not usually covered in a book focusing on natural hazards, but I make the case that there are some common elements between "run of the mill" disasters (the kind described in previous chapters) and the various problems associated 
with climate change and global warming. A common factor among all of them is infrastructure, and the importance of designing for the long-term. In the case of climate change, it's our energy and transportation infrastructure that needs a lot of work. I point out that the time lag between increased $\mathrm{CO}_{2}$ emissions and the worst climate effects can be several hundred years. This time lag makes it difficult for scientists to communicate the true extent of the problem, and also makes it difficult for policy makers to focus on solutions. The real question is, will our great-grandchildren ask, "How could they be so short-sighted?" where "they" means us.

\section{Excerpts from Chapter Eight ('What's all the fuss about global warming?")}

\section{The Time Lag Problem ${ }^{1}$}

In 1993, an elite US military force was involved in a UN-sanctioned mission in Mogadishu, the capital of Somalia in northeast Africa. The larger UN mission was to provide security for NGO's and other groups delivering food aid to Somalia, then in the grip of a deadly famine. The US force was attempting to arrest two lieutenants of a local warlord, Mohamed Farrah Aidid, who had been stealing food aid meant for the citizens of Somalia, and killing or kidnapping aid workers. Despite an array of high tech weaponry and supporting technology, the mission went badly wrong. A key problem was time lag, a simple concept that everyone understands: we often use the phrase "out of sync" to describe situations where the timing of things is a cause for concern.

In the case of Mogadishu, US ground forces, with an armed convoy of Humvees and trucks, had to navigate into and out of the city center during the mission. The convoy was assisted by a surveillance aircraft equipped with high resolution video and a bird's eye view of the city. This aircraft would direct traffic, making sure the convoy could navigate the narrow streets of Mogadishu, avoiding ambushes, road blocks, and other potential choke points. The problem was that the radio frequency used by this aircraft was not the same frequency used by the ground vehicles. Radio messages had to be relayed through several intermediaries: first to the operations commander back at a base outside the city, then to a lower altitude command helicopter, and finally to the convoy. This introduced a delay of perhaps 10 or 15 seconds between the time the radio message was first sent from the surveillance aircraft and when it was finally received on the ground. If the convoy was approaching an intersection, and the surveillance airplane decided the convoy should make a turn, the time lag between transmission and reception meant that by the time the message was received, the lead vehicle had already missed the turn. It's difficult to back up a long convoy (especially if you're taking enemy fire) so the lead vehicle could either keep going, hoping for additional directions, or stop the convoy, and try to get it turned around despite the narrow streets and attendant delays and risks. While the mission was ultimately successful, the resulting confusion and additional time spent in hostile territory contributed greatly to the number of casualties, ultimately leading to the pullout of all US forces from Somalia.

\footnotetext{
${ }^{1}$ p. $212-214$.
} 
We have a similar time lag problem with climate, but instead of 10 or 15 seconds, it's more like several hundred years. We've already put a lot of $\mathrm{CO}_{2}$ into the atmosphere, but for most people, things don't feel so bad right now. The problem is that the full impact of this $\mathrm{CO}_{2}$ won't be felt for a long time, making it difficult to communicate the problem or get support for concerted action. Kunstler (2006) coined the term "long emergency" which nicely describes our climate change dilemma. The implication is that things are going to get a lot worse before they get better. But we won't be around to feel it. Our great-grandchildren will be stuck with the bill.

\section{The Refugee Problem ${ }^{2}$}

I'm sometimes asked by students what the future will look like when global warming starts to happen in earnest. I usually answer that we will see:

1. More summer heat waves, and more deaths from heat stroke, dehydration, and heat-related illnesses.

2. More droughts and wildfires, especially in continental interiors.

3. Accelerating loss of sea ice, glaciers and ice sheets.

4. Rising sea level.

5. More intense storms

6. Increased coastal flooding.

7. Loss of marine species from ocean acidification.

8. Expanding range for tropical diseases.

9. Mass migration of people, from low lying flood-prone areas to higher ground, and from hot equatorial areas to cooler northern regions.

Each of these events, by themselves, has the potential to cause significant social and economic disruption. Taken together, the economic consequences will be profound. Astute readers will notice that most of these things are already happening. Some experts will argue that things are more complicated, and that there is more than one explanation for these phenomena. While this is true, I think a case can be made that for each item on the list, global warming is a key underlying factor.

Consider point \#9, perhaps the most controversial. Bangladesh, which struggles with land loss and resulting loss of economic opportunity associated with rising sea level, has already seen increased migration to nearby countries like India, Malaysia, and Indonesia. The US and Mexico are seeing increased migration from Central America, a region where several countries struggle with high levels of poverty and violence. October and November 2015 saw more than 10,000 unaccompanied children, most from Central America, cross the US-Mexico border. The youngest was six years old. 2015 numbers were nearly double those of 2014. The parents believe their children stand a better chance of being accepted as refugees if they are alone. It is difficult to imagine the level of desperation that would compel parents to send their children away, alone, into an unknown land and unknown future.

2014 and 2015 also saw large increases in human migration from Saharan and subSaharan Africa to Europe, especially through Italy and Spain. People were so desperate to

\footnotetext{
${ }^{2}$ p. $216-218$.
} 
leave that they were willing to cross the Mediterranean in small boats, risking their lives and the lives of their children. More people drowned in the Mediterranean from these crossings in 2014 and 2015 than died in the sinking of the Titanic. During a single week in May 2016, more than 1,000 migrants drowned trying to go from Libya to Italy. Other parts of Europe saw huge increases in migration from Syria during the same period, reflecting that country's brutal civil war. But even here, climate change may have been an underlying factor. Syria experienced a severe drought in the run-up to the war, from 2006 to 2009 . 800,000 people, most of them subsistence farmers, lost their livelihoods, driving internal migration to that country's urban centers, where most became unemployed. Within two years, civil unrest in those centers led to civil war.

Of course there are other explanations for these events, and significant differences among countries. Experts disagree on the main causes. For the problem of tropical disease expansion, for example, the rise of airline travel is certainly a factor, in turn a result of economic growth and the rise of a middle class. For the problem of mass migration, economists tend to blame lack of economic opportunity or a poor business climate. Social scientists blame religious conservatism and lack of gender equality. Political scientists focus on poor governance and political instability. Syria's current civil war is closely tied to the "Arab Spring" that swept through the region between 2010 and 2012, and a population disenchanted with a dictatorial government. Hydrologists will blame falling water tables and poor water management. Demographers (people who study population growth) point to over-population, high birth rates and lack of educational opportunities for women. Military and security experts tend to blame civil war, extremism, or the existence of criminal gangs that engage in human trafficking. All of these factors are relevant, but (with the exception of demography) are not really underlying causes of mass migration. After all, there wouldn't be much profit in human trafficking if no one wanted to leave.

What's the link between climate change and mass migration? Consider African countries such as Chad, Niger, Mali, and Mauritania, suffering water shortages and desertification. Rising temperatures and drought, together with rising population, have led to falling water tables, crop failures, and loss of income for rural families. Most of these countries lack a strong industrial base or major natural resources; agriculture anchors their economy. If you are a subsistence farmer here and lose your agricultural income, you can't walk away from your farm and land a factory job. The region is already sweltering for much of the year, and lacks reliable electricity for air conditioning. So the best and brightest leave, hampering development of a modern industrial economy. The resulting poverty fuels political instability, civil unrest, and a host of other social ills. Young people with no job and no prospects for a better life make easy recruiting targets for criminal gangs or extremist groups. It's possible for a country to overcome these challenges with good governance, infrastructure investment, and economic growth - but it's difficult.

\section{References and Further Reading}

Bowden, M. 1999. Black Hawk Down: a Story of Modern War. Signet, 486 pp. Fink, Sherri. 2013. Five days at Memorial: Life and Death in a Storm-Ravaged Hospital. New York: Crown Publishing Group, 558 pp. 
Kunstler, James Howard. 2006. The Long Emergency: Surviving the End of Oil, Climate Change, and Other Converging Catastrophes of the Twenty-First Century. Grove/Atlantic Inc., 336 pp.

Machiavelli, Niccolò. 1532. The Prince, translated by Harvey C. Mansfield, Jr., 1985 edition. Chicago; University of Chicago Press, 124 pp.

Piguet, Etienne, and Frank Laczko, eds. 2014. People on the Move in a Changing Climate. Dordrect: Springer Science. https://doi.org/10.1007/978-94-007-6985-4.

Robbins, S. 2015. "New Wave of Migrant Children Travelling Alone: US Flooded with Children Fleeing Central America." Associated Press, December 25, 2015.

US Army Corps of Engineers. 2006. "Performance Evaluation, Status and Interim Results." Report 2 of a Series, Performance Evaluation of the New Orleans and Southeast Louisiana Hurricane Protection System. Interagency Performance Evaluation Task Force (IPET).

Van Houten, Carolyn. 2016. "The First Official Climate Refugees in the U.S. Race Against Time." National Geographic (published on-line, May 25, 2016). ${ }^{3}$

Wasdin, Howard E., and Stephen Templin. 2011. Seal Team Six: Memoirs of an Elite Navy SEAL Sniper. New York: St. Martin's Press, 330 pp.

\footnotetext{
${ }^{3}$ A poignant story of a Mississippi Delta community losing its land due to subsidence and sea level rise.
} 